TAPROBANICA, ISSN 1800-427X. January, 2015. Vol. 07, No. 01: pp. 29-37, pls. 15-17.

(C) Research Center for Climate Change, University of Indonesia, Depok, Indonesia \& Taprobanica Private Limited, Homagama, Sri Lanka

www.taprobanica.org

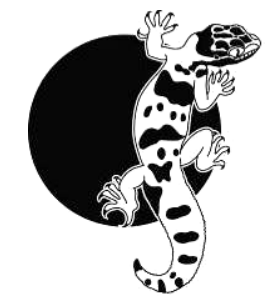

\title{
EFFECTS OF ENVIRONMENTAL ENRICHMENT ON THE SOCIAL BEHAVIOR OF JAVAN SLOW LORIS, Nycticebus javanicus
}

\author{
Section Editor: Colin Groves \\ Submitted: 12 May 2014, Accepted: 16 December 2014 \\ Prescillia Rindang Putri ${ }^{1}$, Richard S. Moore ${ }^{2,4}$, Noviar Andayani ${ }^{3}$, Karmele L. Sanchez ${ }^{2}$ \\ ${ }^{1}$ Research Center for Climate Change (RCCC), University of Indonesia, Gd. PAU Lt. 8.5, Kampus UI, Depok \\ 16424, Indonesia; E-mail: rindangputri@yahoo.com \\ ${ }^{2}$ International Animal Rescue (IAR), Ciapus, Bogor, Indonesia \\ ${ }^{3}$ Department of Biology (FMIPA), University of Indonesia, Kampus UI, Depok 16424, Indonesia, E-mail: \\ nandayani@wcs.org; E-mail: richardmoore60@gmail.com ${ }^{4}$
}

\begin{abstract}
We conducted a behavioural study on rescued captive $N$. javanicus housed at International Animal Rescue Centre, West Java, focussing on the frequency of social interactions in relation to varying amounts of enrichment provided. Three different sized cages were chosen comprising a total of ten slow lorises in groups of five, three and two individuals respectively. After providing extra enrichment, we observed a general increase in all social behaviours in both cages, except for proximity and attack. A significant increase in positive social interactions (clasp interaction) was observed when all data combine after environmental enrichment was given. We made sociograms to visualize the significant results of before and after enrichments. The clasp sociogram before enrichments phase revealed that the only male in both cages acted as the initiator of clasp behaviour to other female actors in the cage. This short study reveals positive signs in increasing certain desired behaviours and the role of individuals within the cage during enrichment.
\end{abstract}

Keywords: captive, critically endangered, ex-situ conservation, primates, reintroduction, sociogram.

\section{Introduction}

Slow lorises (Genus Nycticebus) are small nocturnal strepsirrhine primates from the family Lorisidae (Bearder, 1999). In Indonesia, as many as six species of slow loris have been now proposed: four species in Borneo (two of them are endemic to Borneo, the other two species extend into the Philippines and the Indonesian Island of Bangka respectively), one species in
Sumatra (extending into the Malay Peninsula), and one species in Java (Nekaris \& Jaffe, 2007; Munds et al., 2013). Little is known about the behaviour of slow lorises in the wild, with only two long term studies of $N$. coucang in Malaysia (Barret, 1984; Wiens, 2002; Nekaris \& Bearder, 2007), one of $N$. javanicus in West Java (RodeMargono et al., 2014) and limited others of $N$. 
bengalensis and $N$. pygmaeus. Information yielded from these studies reveals that slow lorises have relatively large home ranges for their body size and can be active for much of the night (Wiens \& Zitzmann, 2003). They were previously considered solitary animals, although recent studies suggest otherwise (Nekaris, 2014), where slow lorises have regular social contact with other conspecifics, and occasionally sleep in groups (Weins \& Zitzmann, 2003; RodeMargono et al., 2014). The lorises' diet consists of flowers, sap, gum, fruits and animal prey (Wiens et al., 2006; Rode-Margono et al., 2014).

Unlike their close relatives, the galagos, that use leaping as their preferred locomotion, members of subfamily Lorisinae (pottos and lorises) do not jump and are known for their characteristic slow climbing locomotion (Nekaris \& Bearder, 2007). Some studies suggest their slow locomotion is related to the high amount of toxic insects in their diet (Nekaris \& Rasmussen, 2003), and others suggest it indicates their need to detoxify their high-energy plant second compounds (Wiens et al. 2006).

The Javan slow loris ( $N$. javanicus, Geoffroy,1812) is endemic to Java (Groves, 2001). The distinctive facial markings of this species are characterised by a white diamond located between the eyes and stretching up to the forehead surrounded by a bold black fork-mark covering the eyes, ear and the crown (Nekaris \& Jaffe, 2007). According to the IUCN Red List, Javan slow loris is considered as Critically Endangered with a rapidly decreasing population trend (Nekaris et al., 2013). Habitat loss and forest degradation are major factors in their decline; more recently, illegal trade appears to be the biggest threat (Shepherd, 2010).

A systematic reintroduction program for confiscated and rescued slow lorises was started by International Animal Rescue in 2010. This program aims to maintain this species' population by rehabilitating and then releasing them back to habitat from within their historical range (Moore, 2012). The reintroduction program employs a "soft-release strategy", following the IUCN Guidelines for Non-human Primate Re-introductions (IUCN, 2002). The first step in the rehabilitation process involves a medical check-up on all animals entering the center (IAR, 2010). Animals are then quarantined and monitored to observe their survival skills before being assessed as suitable for release (Moore, 2012). Not all lorises are suitable for release due to poor health and/or teeth condition or because of behavioural abnormalities. To avoid being bitten by the venomous slow lorises, market traders habitually cut or pull out the animal's teeth with nail clippers or pliers (Nekaris et al., 2009).

During the period of captive care, certain aspects of an animals' natural environment need to be maintained; for example, nutritional needs (freedom from hunger and thirst), comfort (being free from fear and stress), and also the need to express its natural behavior (UKFAWC, 2011). Stress behaviour in a captive environment can be triggered by group composition and size, individual experience, and also the environmental conditions in captive care (Mallapur, 2005; Moore, 2012). Animals in an enriched cage environment show more development of important survival skills needed for release (Vargas \& Anderson, 1999). Through environmental enrichment, the level of stress that can relate to the expression of stereotypic behaviours (such as pacing and rocking) can be minimized, and subsequently encourage active natural behavioural diversity (Robert et al., 1999). This process can increase the success of survival in animals released back to the wild (Carstead \& Shepherdson, 1994; Shepherdson, 2007; Vargas \& Anderson, 1999). Animals in a reintroduction programme must have the capabilities to feed, forage for wild food, show nesting behaviour, show natural social behaviour and display limited or no abnormal behaviour (Collins \& Nekaris, 2008; Moore, 2012; Streicher \& Nadler, 2003).

Since 1985 the Animal Welfare Regulation Act has attempted to maintain the welfare of animals in captivity. Captive practitioners, zoo management, and animal researchers use environmental and behavioural enrichment to create a physical environment promoting psychological well-being of non-human primates (Shepherdson, 2007). Studies of environmental enrichment include: feeding enrichment, use of inanimate toys, varying substrates and group-housing arrangement depending on the animal's specific behavioural needs (Reinhardt et al., 1995; Brent \& Belik, 1996; Vargas \& Anderson, 1999; Kerridge, 2005; Maloney et al., 2006; Cummings et al., 2007; Dishman et al., 2009). Whilst 
environmental enrichments have been used in a number of studies on non-human primates [e.g. Baboons (Brent \& Belik, 1996); Lemurs (Kerridge, 2005; Maloney et al., 2006; Dishman et al., 2009); Marmosets (Robert et al., 1999); and Squirrel monkeys (Spring et al., 1997)], the information about the effect of environmental enrichment on slow lorises is scarce. Schulze \& Meier (1995) used environmental enrichment in their study with the purpose of avoiding physical stress while observing the behaviour of Loris tardigradus nordicus, but the effect of the enrichment given was not recorded.

To survive in the wild, animals need to have a diverse set of behaviours, which are often lost in captive situations due to lack of environmental and social stimuli (Mallapur \& Choudhury, 2003). Carlstead \& Shepherdson (2000) gave feeding enrichments to the captive lorises to give them an opportunity to vary and increase their natural behaviours. In this study we focused on determining if there was any influence on Javan slow loris's social behaviour depending on different types of food enrichments given. The aim was to reduce boredom and restricted movements in a limited cage size by adding branches and rubber ropes for locomotion. We focused on whether enrichment could increase social behaviour among individuals, and observed the interactions within group members. We expected the study to contribute information necessary for a deeper understanding of the behavioural needs of captive Javan slow lorises, which will be important to ensure their wellbeing in captivity and enhance their chances of survival in the wild.

\section{Materials and Methods}

Study site: The study was carried out at International Animal Rescue (IAR), Bogor, Indonesia. IAR is a rehabilitation centre for confiscated primates rescued from the animal trade. As slow lorises are nocturnal, shy and reasonably solitary animals, they are housed in semi-natural cages of varying sizes, in a quiet location, away from the centre, which is restricted for visitors.

Captive enclosures and study group: Ten Javan slow lorises were chosen for this study. For purposes of comparison we chose lorises with different sex compositions, We selected cages of three different sizes, comprising different enrichment materials: cage J5 (2m x $2 \mathrm{~m})$ was a rope net cage with a soil floor and contained one male and one female; cage $18(2 \mathrm{~m} \mathrm{x} 2 \mathrm{~m})$ was a wire cage with a cement floor with one male and two females; and a sanctuary cage $(4 \mathrm{~m} \times 4 \mathrm{~m})$ was a wire cage with a cement floor with one male and four females. The condition in each cage also differed. In the sanctuary cage live substrates were present (bamboo and a mango tree) along with other hanging branches, rubber ropes, feeding platforms, a nest box, and a sleeping cylinder made from weaved bamboo. cages J5 and 18 had similar substrates only without live substrates as these cages were newly built. There was a dead branch hanging in cages 18 and $\mathrm{J} 5$, live branches, as well as rubber ropes, a food container made from bamboo hanging on the cage wire, a nest box and a sleeping cylinder made from a gunny-sack and bamboo in the sanctuary cage. The animals were provided with various enrichments (Fig. 1) and places to hide from keepers and conspecifics. During the night, cages were lit with dim red halogen lights. Daily feeding occurred three times a night with varied natural foods (mixed fruits, insects, sago palm weevil larva, and bird eggs, etc.).

Data collection: We monitored the slow lorises in the cages for one month between 8 August and 5 September 2010. Data were collected using the all-occurrence sampling method during 20 min intervals for each phase of enrichment. The all-occurrence sampling method was used owing to the relatively unbiased results (Zinner et al., 1997). The observational condition was excellent in the cages and therefore, for the purpose of recording "actor-receiver" interactions in social behaviour, all-occurrence sampling was thought appropriate for this study (Altmann, 1974). To help in recognising and differentiating between "the actor" and "the receiver" during the study, we spent the first 5 nights conducting a pilot study to become familiar with individuals and to reduce data bias.

We observed the animals' natural marks to help distinguish among individuals in each cage, rather than marking them with tags or bands to avoid annoyance to the animal's natural behaviours. Body colour, head marking, and other unique marks characteristic of each individual were used to differentiate among individuals (Fig. $2 \& 3$ ). After this period we could confidently identify all lorises in the study. Besides recognising the individuals, the 
pilot study was also beneficial to the observer to test the sampling methods, construct an sociogram and get used to recording the behaviours of the animals to yield more systematic and effective data (Dawkins, 2007).

Data were recorded in two phases: before and after enrichment. Two types of enrichment were given in each cage during enrichment phases: (1) a hollow bamboo $\log$ (approximately $50 \mathrm{~cm} \times 6$ $\mathrm{cm}$ ) with holes on the surface larger than the hand of a slow loris, filled with crickets; and (2) a peeled bamboo log with small holes cut through the surface and filled with honey. Besides food enrichments we also added fresh tree $\log$ as environmental enrichments to encourage gouging behaviours, and more branches and rubber ropes to provide extra substrates for locomotion.

We focused on recording the social behaviours of lorises and observed them continually during any bout of grooming, attack, proximity, leave, social explore, sniff, clasp, and approach. These behaviours followed the sociogram produced by Fitch-Snyder \& Schulze (2000). We recorded the data approximately 1 meter from cages and on one or two sides of the cages. Data were recorded on a paper worksheet with additional information such as start time, end time, date, time, location and weather.

Statistical analysis: We conducted the statistical analysis with SPSS 17.0 software for Windows. We explored differences between enrichment phases and between cages using non-parametric tests. The non-parametric Wilcoxon signed-rank test was used to make statistical comparison between phases of the enrichment given to each cage. Significance values were set at $p=0.05$. Although parametric tests are more powerful statistically, they were not chosen in this study due to the small sample size.

We used Social Network Analysis (SNA) to analyze the social relationship for a deeper understanding of animal social and complex sociality (Wey et al., 2008). SNA can represent information about ties among actors through matrices and a graphic known as a network diagram or sociogram (Hanneman \& Riddle, 2005; Wey et al., 2008; Coleing, 2009). To visualize the sociograms We used NetDraw (version 2.104, which is distributed along with UCINET by Borgatti et al. (2002). In the sociograms, actors are symbolized as nodes which are connected by social ties from interactions between actors (Wey et al., 2008). Since the sociograms we used were directional (with arrows to show the direction of interaction) and weighted (with value of interaction between actors), in-degree and outdegree of an actor could be distinguished to show the relationships between actors (Hanneman \& Riddle, 2005). In-degree is the number of ties directed toward to an actor, in this case the number of social interactions it received, and out-degree is the number of ties the actor emitted to other actors (Coleing, 2009; Sueur et al., 2011; Wey et al., 2008).

We did not include data from cage J5 in the analysis because of incomplete data: Guaro, a male, became stressed by an aggressive female conspecific, Jane, which caused him to stop eating, and he also became sick during the observational period, which led to a decision from the keepers to move him to a different cage, separate from Jane.

\section{Results}

We combined all data sets to test if there was any significant difference between the two phases of enrichment in both cages. Only clasp showed a significant difference. Clasp behaviour significantly increased after enrichment was provided in both cage 18 and cage S9 (Wilcoxon signed-rank test, $p<0.05$, Fig. 4). There were no other significant differences found in the behaviours observed in these two cages. Means of the occurrence of each behaviour of all data are presented in Table 1.

We then separated the data based on each cage to see if there any significant difference between two phases of enrichment in each cage. No significant differences were found in any behaviour between the two phases of enrichment in both cages 18 and S9.

Clasp - before enrichment: Figure 5 shows the frequency (as weights) and the direction of the clasp interactions between the actors before the enrichments was given to both cage 18 and S9. In this Figure, male is represented by a red node and females by blue nodes. It seen in cage 18 , a reciprocate clasp interaction only happened between two actors, Craight and Opi, while Kiki was never seen engaging in clasp interaction with other individuals in cage 18. Similar to 
cage 18, there are only two actors (Cristin and Palupi) shared clasp interaction in cage S9, although interaction in $\mathrm{S} 9$ was not reciprocated. Palupi acted as the initiator of the clasp behavior in the cage and seen only once during the observation before enrichments were given. Singgih, as the only male in cage S9, was not recieve or initiate a clasp to other actors in cage S9.

The group cohesion statistic was relatively low (0.375 from a maximum 1.0, revealing lesscompacted interactions of clasp among the actors in both cage. The network also indicates that the group was not compact (very low density, 7\%), revealing that there was limited actors engaging in clasp interaction.

The clasp sociogram only showed reciprocity interactions between actors in the cage 18 . Reciprocity is represented by the thickening of each tie linking the nodes in the sociogram; thick ties indicate a reciprocity relation in giving and receiving clasp between two actors, while thin ties show that, while there are clasp behaviours between two actors, there are no reciprocity interactions (only giving or only receiving).

Clasp - after enrichment: While before enrichment phase some actors are not engaging in clasp interaction, the sociogram of clasp interaction after enrichment phase (Fig. 6) showed that actors in both cages engaging in clasp interaction.This is indicated by every nodes connected with ties between them. Although not all ties showed reciprocity interaction, the sociogram of clasp in both cage showed a compact interaction: cohesion has the maximum value and the interaction of clasp after enrichments were given is also dense $(100 \%$ density).

The sociogram outdegree in cage 18 revealed that the only male in the cage, Craight was the active initiator of clasping other two actors while Kiki received the most of clasps from the other actors in the cage. Sociogram in cage 18 also showed reciprocity interaction between actors except clasp behavior between Opi and Kiki (both female).

Interestingly, the sociogram of clasp in cage S9 also showed that the only male in the cage, Singgih acted as a central role after the enrichments were given. Sociogram showed that Singgih acted as both giver and reciever of clasping interactions. On the other hand, one of the females in cage S9, Denok, received the most of clasps from the other actors (both female and male). Though clasp interaction was increased in cage S9 after the enrichments were given, there was no reciprocity of interactions between actors found in cage S9.

Table 1: Mean \pm SD of all data set using Wilcoxon signed-rank test; *significant values

\begin{tabular}{|c|c|c|c|}
\hline \multirow{2}{*}{ Variable } & \multicolumn{2}{|c|}{ enrichment } & \multirow{2}{*}{$\begin{array}{c}\mathrm{P} \\
\text { value }\end{array}$} \\
\hline & before & after & \\
\hline Grooming & $0.7 \pm 1.4$ & $0.9 \pm 1.8$ & 0.234 \\
\hline Attack & $0.2 \pm 0.6$ & $0.2 \pm 0.6$ & 0.923 \\
\hline Proximity & $0.6 \pm 0.9$ & $0.6 \pm 0.6$ & 0.645 \\
\hline Leave & $1.7 \pm 1.3$ & $1.9 \pm 1.8$ & 0.940 \\
\hline Social explore & $0.3 \pm 0.5$ & $0.3 \pm 0.7$ & 0.581 \\
\hline Sniff & $0.0 \pm 0.2$ & $0.0 \pm 0.2$ & 0.655 \\
\hline Clasp* & $0.1 \pm 0.3$ & $0.5 \pm 1.3$ & 0.005 \\
\hline Approach & $3.8 \pm 3.0$ & $4.0 \pm 3.0$ & 0.582 \\
\hline
\end{tabular}

Table 2: Indices of clasp before and after enrichment

\begin{tabular}{lrr}
\hline \multirow{2}{*}{ Indices of clasp } & \multicolumn{2}{c}{ enrichment } \\
\cline { 2 - 3 } & before & after \\
\hline Network density & 0.07 & 1.00 \\
Weighted density & 0.50 & 9.50 \\
Average distance & 1.00 & 1.00 \\
Cohesion & 0.37 & 1.00 \\
\hline
\end{tabular}

\section{Discussion}

In this study on social behaviour in captive Javan slow lorises, it was expected that enrichment would increase activity levels [as in the study on ring-tailed lemurs by Dishmann et al. (2009)]. Figure 4 shows that, in general, enrichment affected social behaviours increased (only significantly increased for clasp behavior), except for proximity and attack, which showed a decline. Our findings contrast with a study by Bloomsmith et al. (1988) on chimpanzees, where feeding enrichment was not effective as a way to achieve the goal of increased levels of social behaviour. The significant increase in clasp after enrichment indicated that the enrichment gave a positive influence in this social behaviour in the captive lorises in this study. Clasps in captive lorises represent initiation of an active affiliative (friendly) interaction between individuals, and also occurs when individuals are being held by conspesifics while grooming (Ehrlich \& Musicant, 1997). 
Conversely, Maloney et al. (2006) observed, during exposure to feeding enrichment (a wire box filled with whole grapes, apples divided by six or both) in black lemurs, an increase in the incidence of grooming. Since we used all types of enrichments simultaneously rather than focusing on one, effects on increasing social behaviour could not be distinguished based on the type of enrichment given. Further studies would be necessary to investigate the effect of each enrichment type independently on captive slow lorises.

The cages of our study were already enriched with various substrates (either dead plants hanging across the cage or live plants growing from the ground) to promote locomotion on different substrates as seen in the wild. Cages had hiding places and nest boxes as recommended in the design by Fitch-Snyder et al. (2008). Possibly, the slight decrease of proximity in both cages was due to restricted viewing during observation, which could have led to some unseen incidences of proximity. Yet the study of pair-housed juvenile rhesus macaques by Schapiro \& Bloomsmith (1994) found that enrichment did not affect the time spent in proximate locations of each other (within $8 \mathrm{~cm}$ ).

Attack behaviour in both cages showed a slight decrease after enrichment was given, although not statistically significant. This finding was comparable to the study conducted by Boccia \& Hijazi (1998), where enrichment caused a significant decline in aggression in pigtail macaques. Slow loris in the wild are rarely observed in territorial fights; however, for slow lorises in captivity, aggression occurs much more often (Ehrlich \& Musicant, 1977; Wiens, 2002), probably owing to the restricted enclosures and reduced opportunities of avoicance, compared to home ranges sizes in the wild. These preliminary results suggest that enrichment devices can decrease aggression among captive individuals, to achieve reproductive success and a better psychological well-being (Carlstead \& Shepherdson, 1994). Owing to the short duration of the study, it may prove to be the case that more significant results can be obtained with a larger data set.

Ehrlich \& Musicant (1977) found that, once familiar to each other, captive slow lorises showed no avoidance to conspecifics, and a high occurrence of approaches and proximity to each other. Comparison of data in the enrichment phases in each cage revealed only one behavior with significant increase. While this result is in accord with studies of Maloney et al. (2006), where enrichment increased social behaviours, we need to be cautious when interpreting these results owing to the small sample size and short duration of the study. The results are promising, even though more lengthy studies are needed to validate this preliminary result.

Sociograms for both cages 18 and S9 revealed increases in actors engaging in clasp interactions after enrichments were given. The only male in both cage (Craight in cage 18 and Singgih in cage S9) acted as the initiator of the clasp interaction toward females in each cage. One female actor in cage 18, Opi acted as both giver and reciever of the clasp interaction, while Kiki acted only as reciever. In cage S9, only Denok received the most clasps in the female group. It was expected there was a sex-based difference interaction in the cage in line with a study conducted by Ramadhan (2010), where a captive male Javan slow loris showed more activity in social interaction to the female conspecific than did the female. Conversely, a study by Radhakrishna \& Singh (2002) revealed that there was no difference in social behavior between male and female in captive slender lorises.

The claps sociogram in cage 18 after enrichment phase revealed that there were reciprocating interactions. A study by McCowan et al. (2008) found that high rates of affiliate reciprocity within a social group indicates that the network is more cohesive, which is comparable to the result in this study, where the clasp sociogram after enrichments in cage 18 showed high reciprocity relationships which affected the cohesiveness of the network (with cohesion $=1.00$, the maximum possible value). This result may be due to the small network size, allowing for more interactions between actors in cages to build up an exchange/reciprocity relationship compared those in a larger network size (Hanneman \& Riddle, 2005). The small network size offered the opportunity for the lorises to get to know each other relatively well and therefore conduct many social interactions. The result suggests that, once familiar to each other, captive slow lorises kept in groups can reciprocate interactions between individuals in 
the cage, as shown by the high occurrence of clasp, so supporting a study by Ehrlich and Musicant (1977) on captive Malayan slow lorises that spent the majority of their time walking toward to conspecifics. A useful future study would be to analyse the effect on the harmony or social interactions in a group if an individual, who acted as the main initiator in this group, were to be removed or absent for some reason.

While a good enclosure design has been developed to promote a more natural cage to fulfil slow lorises' needs (Fitch-Snyder et al., 2008), slow lorises may still suffer in captivity owing to the fact they are such wide ranging animals (Wiens, 2002). Urine marking and scent glands in lorises are important in order to communicate and mark territory, and for use in sexual behaviors (Fisher et al., 2003 on Nycticebus pygmaeus; Schulze \& Meier, 1995 on Loris tardigradus nordicus). An increase in such social behavioural, albeit not a significant one, could be an indication that feeding enrichment encourages such behaviours. The present study was conducted over a short period and focused on enrichment exposure in relation to behavioural changes, so the results should be taken cautiously, and more studies would be needed to help verify these data, and to support the suitability of the enrichment given. For example, further studies on enrichment, focusing on the exposure period of the enrichment; enrichment replacement; and feeding manipulation would be necessary to explore optimal types of enrichment that would help in the welfare and conservation of captive slow lorises. Finally, it is important to test the practical implementation of enrichment in captivity, as each case, animal and enclosure is different.

\section{Acknowledgements}

We would like to thank Nicolen de Lange, Darma Sukama, and all the staff members and animal keepers at International Animal Rescue (IAR), Ciapus, Bogor, Indonesia, for allowing access to their facility and all their help during data recording. First author thanks her supervisors Jarot Arisona and Noviar Andayani for all their guidance. We thank all the research fellows for assistance during study and peers that help reviewing and commenting on the earlier draft of the manuscript. Anargha Setiadi is acknowledged for kindly sketching the lorises.
Finally we would like to thank Anna Nekaris for her advice on observational methods, and Lee Harding for reviewing the manuscript.

\section{Literature cited}

Altmann, J., 1974. Observational study of behaviour: sampling methods. Behaviour, 48: 141.

Bearder, S.K., 1999. Physical and social diversity among nocturnal primates: a new view based on long term research. Primates, 40: 267-282.

Bloomsmith, M., P.L. Alford, and T.L. Maple, 1988. Successful feeding enrichment for captive chimpanzees. American Journal of Primatology, 16: $155-164$.

Boccia, M.L. and A. Hijazi, 1998. A foraging task reduced agonistic and stereotypic behaviors in pigtail macaque social groups. Laboratory Primate Newsletter, 37: 1-5.

Borgatti, S.P., M.G. Everett, and L.C. Freeman, 2002. Ucinet for Windows: Software for Social Network Analysis. Harvard, MA: Analytic Technologies.

Brent, L. and M. Belik, 1996. The response of group-housed baboon to three enrichment toys. Laboratory Animals, 31: 81-85.

Carlstead, K. and D. Shepherdson, 1994. Effect of enviromental enrichment on reproduction. Zoo Biology, 13: 447-458.

Carlstead, K. and D. Shepherdson, 2000. Alleviating stress in zoo animals with environmental enrichment. In: The biology of animal stress: basic principles and implications for animal welfare. Eds. G.P. Moberg \& J.A. Mench. CABI Publishing. Pp. 337-354.

Coleing, A., 2009. The application of social network theory to the animal behavior. Bioscience Horizons, 2: 32-43.

Collins, R. and K.A.I. Nekaris, 2008. Release of greater slow lorises, confiscated from the pet trade, to Batutegi Protected Forest, Sumatra, Indonesia. In: Soorae, P.S (ed.). Global Re-introduction Perspectives, IUCN Reintroduction Specialist Group Abu Dhabi: 192-195.

Cummings, D., J.L. Brown, M.D. Rodden, and N. Songsasen, 2007. Behavioral and physiologic responses to enviriomental enrichment in the 
maned wolf (Chysocyon brachyurus). Zoo Biology, 26: 331-343.

Dawkins, M.S., 2007. Observing Animal Behavior: Design and analysis of quantitatif study. Oxford University Press, Oxford: 176.

Dishman, D.L., D.M. Thomson, and N.J. Karnovsky, 2009. Does simple feeding enrichment raise activity levels of captive ring-tailed lemur (Lemur catta)?. Applied Animal Behavior, 116: $88-95$.

Ehrlich, A., and A. Musicant, 1977. social and individual behaviors in captive slow lorises. Behavior, 60: 195-220.

Fisher, H., R.R. Swalsgood, and H. Fitch-Snyder, 2003. Odor familiarity and female reference for males in threatened primate, the pygmy loris Nycticebus pygmaeus: application for genetic management of small populations. Naturwissenschaften, 90: 509-512

Fitch-Snyder, H., and H.Schulze, 2000. Husbandry manual for Asian lorisines (Nycticebus and Loris) <www.loris-conservation.org > Accessed on 2 September 2010.

Fitch-snyder, H., H. Schulze, and U. Streicher, 2008. Enclosure Design for captive slow and pygmy lorises. Primates of The Oriental Night, ?:123-135.

Groves, C.P, 2001. Primate Taxonomy. Smithsonian Institute Press, Washington DC: 350.

Hanneman, R. and M. Riddle, 2005. Introduction to Social Network Methods <www.faculty.ucr.edu> Accessed on 1 July 2010.

IAR (International Animal Rescue), 2010. The slow loris in Indonesia: the rise in illegal wildlife trade. Proceedings of the Seminar on Slow Loris Conservation: 55.

IUCN, 2002. Guidelines for Nonhuman Primate Re-introductions. Re-introduction News, 21: 2953.

Kerridge, G.J, 2005. Enviromental enrichment to address behavioral differences between wild and captive black-and-white ruffed lemurs (Varecia variegata). American Journal of Primatology, 66: $71-84$
Mallapur, A., 2005. Managing primates in zoos: Lesson from animal behavior. Current science, 89: 1214-1219.

Mallapur, A. and B.C. Choudhury, 2003. Behavioral abnormalities in captive nonhuman primates. Journal of Applied Animal Welfare Science, 6: 275-284.

Maloney, M.A., S.T. Meiers, J. White, and M.A. Romano, 2006. Effect of three food enrichment items on the behavior of black lemurs (Eulemur macaco macaco) and ringtailed lemurs (Lemur catta) at the Henson robinson zoo, Springfield, Illinois. Journal of Applied Animal Welfare Science, 9: 111-127.

McCowan, B., K. Anderson, A. Heagarty, and A. Cameron, 2008. Utility of social network analysis for primates behavioral management and wellbeing. Applied Animal Behavior, 109: 396-405.

Moore, R.S., 2012. Ethics, ecology and evolution of Indonesian Slow Lorises (Nycticebus spp.) rescued from the pet trade. $\mathrm{PhD}$ thesis, Oxford Brookes University.

Munds, R.A., K.A.I. Nekaris, and S.M. Ford, 2013. Taxonomy of the Bornean slow Loris, with a new species Nycticebus kayan (Primates, Lorisidae). American Journal of Primatology, 75: 46-56.

Nekaris, K.A.I., 2014. Extreme primates: Ecology and evolution of Asian lorises. Evolutionary Anthropology, 23:177-187.

Nekaris, K.A.I. and S.K. Bearder, 2007. The strepsirrhine primates of Asia and Mainland Africa: diversity shrouded in darkness. In:. Campbell, C., A. Fuentes, K. MacKinnon, M. Panger, and S. K. Bearder (eds.). Primates in Perspective. Oxford University Press, Oxford: 2445.

Nekaris, K.A.I. and S. Jaffe, 2007. Unexpected diversity of slow lorises (Nycticebus spp.) in the Javan pet trade: implications for slow loris taxonomy. Contributions to Zoology, 76: 187196.

Nekaris, K.A.I. and D.T. Rasmussen, 2003. Diet of the slender loris. International Journal of Primatology, 24: 33-46.

Nekaris, K.A.I., M. Shekelle, Wirdateti, E.J. Rode, and V. Nijman, 2013. Nycticebus javanicus. In: 
IUCN 2013. IUCN Red List of Threatened Species. Version 2013.1 <www.iucnredlist.org>

Reinhardt, V., C. Liss, and C. Stevens, 1995. Social housing of previously single-caged macaques: what are the options and the risks?. Animal Welfare, 4: 307-328.

Robert, R.L., L.A. Royburd, and J.D. Newman, 1999. Puzzle feeders and gum feeders as enviromental enrichment for common marmosets. Contemporary topics, 38: 27-31.

Rode-Margono, E.J., V. Nijman, Wirdateti, and K.A.I. Nekaris, 2014. Ethology of the Critically Endangered Javan slow loris Nycticebus javanicus É. Geoffroy Saint-Hilaire in West Java. Asian Primate Journal, 4: 27-41.

Schapiro, S.J. and M. Bloomsmith, 1994. Behavioral effects of enrichment on pair-housed juvenile rhesus monkey. American journal of primatology, 32: 159-170.

Schulze, H. and B. Meier, 1995. Behavior of captive Loris tardigradus nordicus: a qualitative description, including some information about morphological bases of behavior. In: Alterman, L. G. Doyle, M.K. Izard (eds.). Creatures of the Dark. Plenum Press, New York: 221-249.

Shepherd, C., 2010. Loris trade - domestic and international. Presentation at the Seminar on Slow Loris Conservation, 9 December 2010.

Shepherdson, D., 2003. Enviromental enrichment: past, present, and future. International Zoo Yearbook, 38: 118-124.

Spring, S.E., J.O. Clifford, and D.L. Tomko, 1997. Effect of environmental enrichment devices on behaviors of single- and group-housed squirrel monkeys (Saimiri sciureus). Journal of the American Association for Laboratory Animal Science, 36: 72-75.

Streicher, U. and T. Nadler, 2003. Re-introduction of pygmy lorises in Vietnam. Reintroduction News (Newsletter of the IUCN Reintroduction Specialist Group), 23: 37-40.

Sueur, C., A. Jacobs, F. Amblard, O. Petit, and A.J. King, 2011. How can social network analysis improve the study of primates behavior? American Journal of Primatology, 71: 1-17.
UKFAWC (UK farm animal welfare council), 2011. Five freedom <www.fawc.org.uk> Accessed on 11 May 2011.

Radhakrishna, S. and M. Singh, 2002 Social behavior of slender loris (Loris tardigradus lydekkerianus). Folia Primatology, 73: 181-196.

Ramadhan, R, 2010. Pola aktivitas kukang jawa (Nycticebus javanicus) di kandang rehabilitasi satwa International Animal Rescue (IAR), Bogor. Undergraduate Disertation, University of Indonesia.

Vargas, A. and S.H. Anderson, 1999. Effect of experience and the cage enrichment on predatory skill of Black-footed ferret (Mustela nigripes). Journal of Mammalogy,80: 263-269.

Wey, T., D.T. Blumstein, W. Shen, and F. Jordan, 2008. Social network analysis of animal behavior: a promising tool for the study of sociality. Animal behavior. 75: 333-344.

Wiens, F, 2002. Behavior and ecology of wild slow lorises (Nycticebus coucang): social organisation, infant care system and diet. PhD thesis. Bayreuth University.

Wiens, F., and A. Zitzmann, 2003.Social dependence of infant slow lorises to learn diet. International Journal of Primatology, 24: 10071021.

Wiens, F., A. Zitzmann, and N. Hussein, 2006. Fast Food for Slow Lorises: Is Low Metabolism Related to Secondary Compounds in High- Energy Plant Diet?. Journal of Mammalogy, 87: 790-798.

Zinner, D., J. Hindahl, and M. Schwibbe, 1997. Effect of temporal sampling pattern of alloccurence recording in behavioral studies: many short sampling periods are better than a few long ones. Ethology, 103: 236-246. 


\section{PLATE 15}

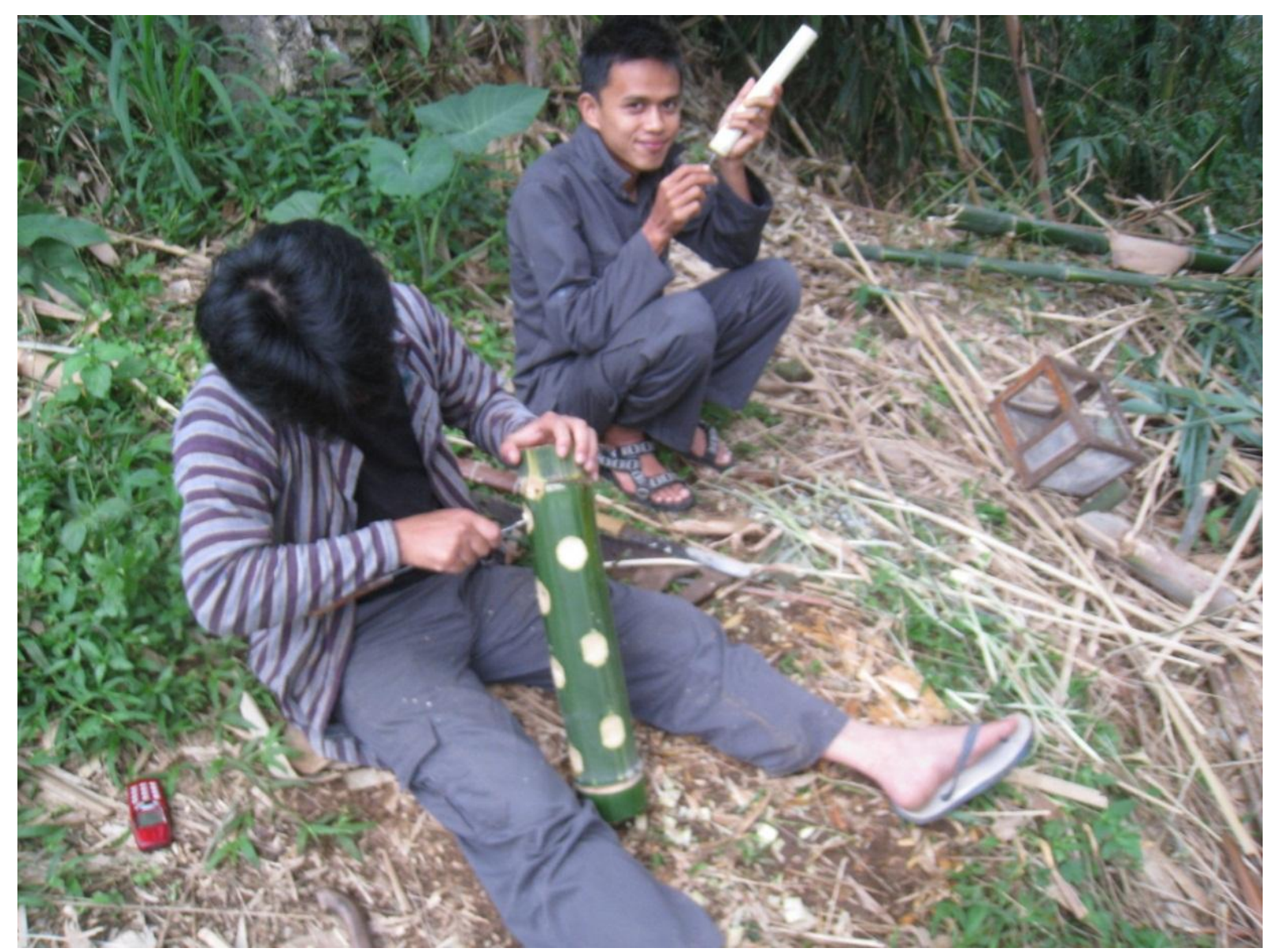

Figure 1: Keepers in the process of the enrichment-making. Mursid (on the left) made a hole on the big bamboo $\log$ and filled it with crickets and Firman (on the right) peeled the small bamboo and filled it with honey.
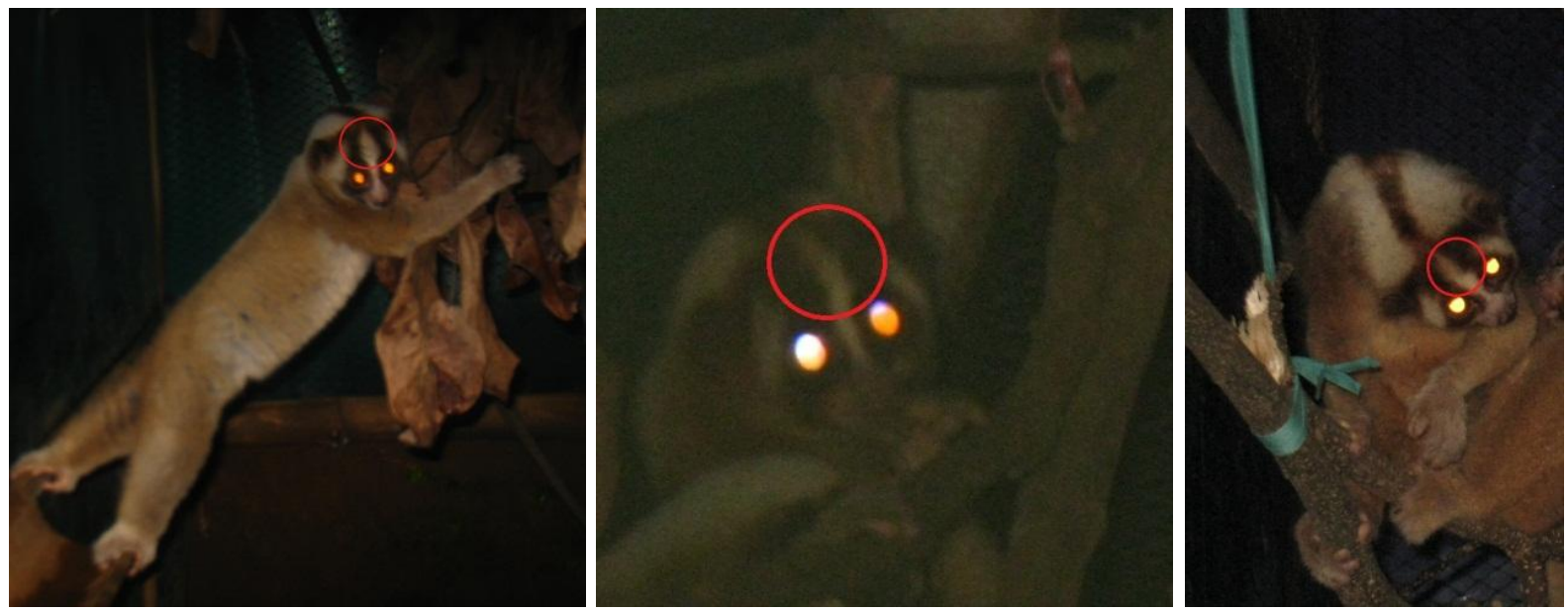

Figure 2: Individuals of cage 18 at International Animal Rescue, Bogor, Indonesia 


\section{PLATE 16}

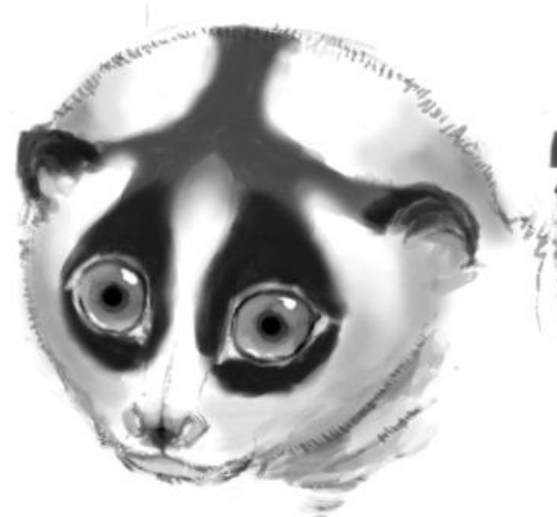

Singgih

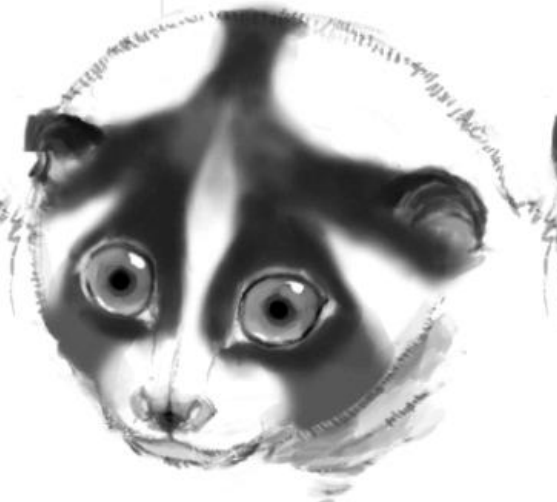

Cristin
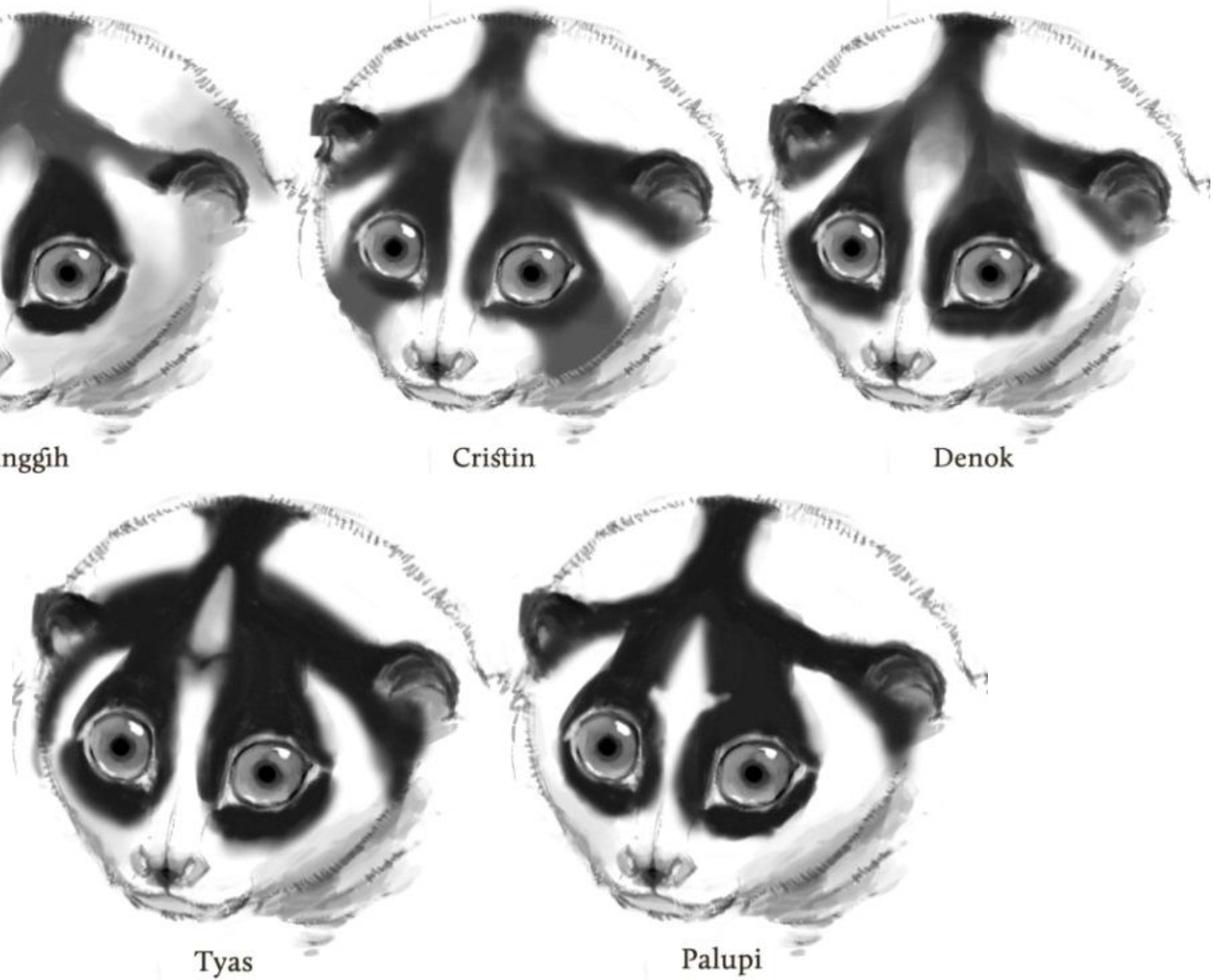

Figure 3: Individuals of Cage S9 at International Animal Rescue, Bogor, Indonesia (Illustrated by Anargha Setiadi).

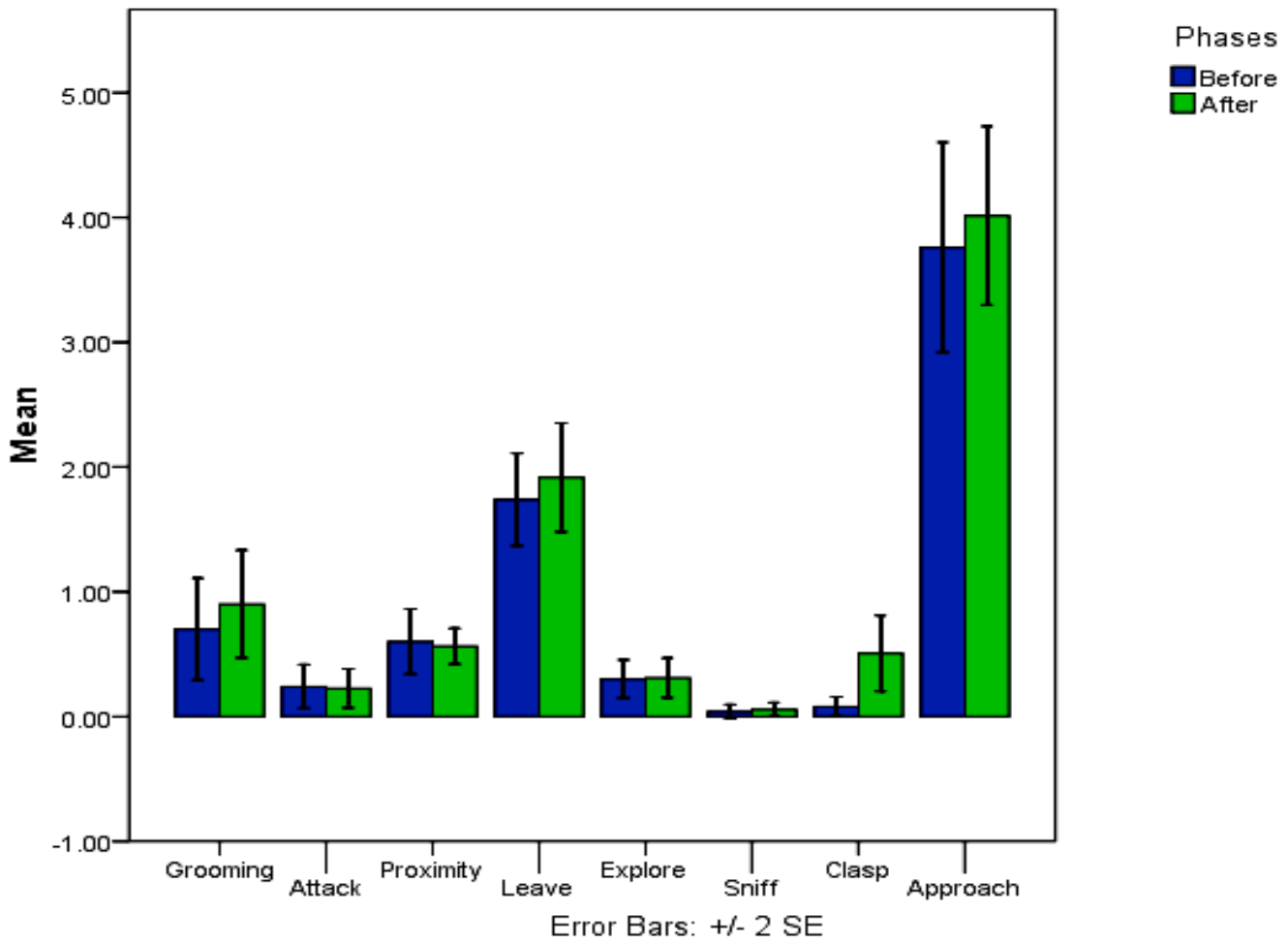

Figure 4: Mean of samples $\pm S D$. Before enrichment $(\mathrm{n}=50)$, after enrichment $(\mathrm{n}=71)$. 


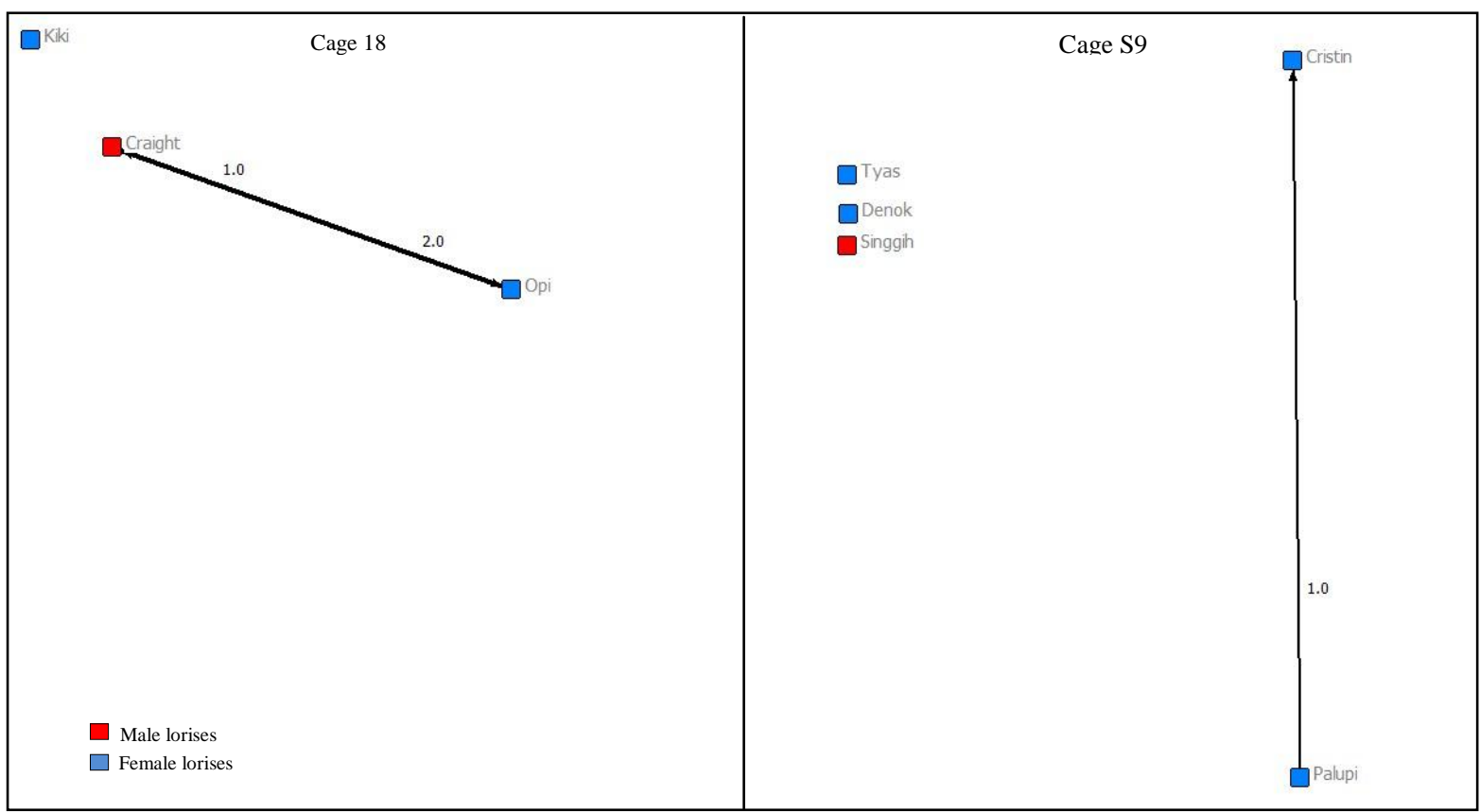

Figure 5: Weighted sociogram of clasp before the enrichment phase. The weights indicate frequency of clasp interaction between actors. The darker ties represented a reciprocate interactions between actors while the lighter one represented a one-way interaction.

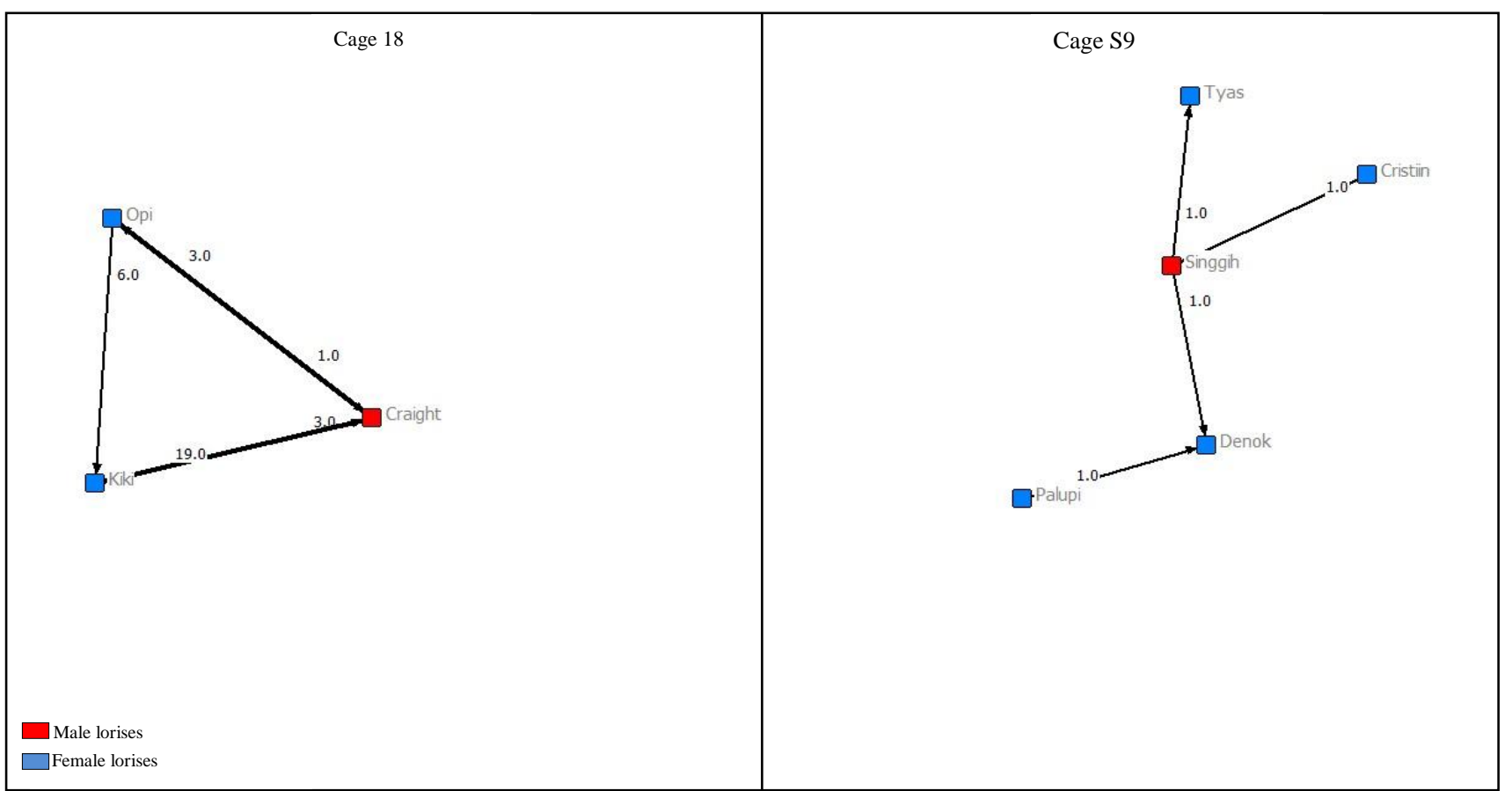

Figure 6: Weighted sociogram of clasp after the enrichment phase. The weights indicate frequency of the clasp interaction between actors. The darker ties represented a reciprocate interactions between actors while the lighter one represented a one-way interaction. 